\title{
Formulation of Liposome using Sappan wood (Caesalpinia Sappan L.) Ethyl acetate Fraction as an activate compound
}

\author{
FEBRIYENTI ${ }^{*}$, DENI NOVIZA ${ }^{2}$, HENNY LUCIDA ${ }^{3}$, \\ NETTY SUHARTI ${ }^{4}$ and PUTRI BHANA PINTO ${ }^{5}$
}

Faculty of Pharmacy Universitas Andalas, Padang, Indonesia 25163.

*Corresponding author E-mail: febriyenti74@gmail.com

http://dx.doi.org/10.13005/ojc/340355

(Received: September 10, 2017; Accepted: February 01, 2018)

\begin{abstract}
The purpose of this study is to determine the characteristics of liposome Caesalpinia Sappan wood ethyl acetate fraction (SWEAF) as an active compound. Liposome was prepared by using two methods: Thin Layer Hydration (TLH) and Reversed Phase Evaporation (REV) methods. Liposome composition was 1 part of the SWEAF and 6 parts of the liposome component (phosphatidyl choline and cholesterol with an equally large molar ratio). Both methods produce red-colored liposome dispersion. When examined with transmission electrone microscope, both methods yielded a spherical and unilamellar liposome. The TLH method produces liposome with a particle size of 2,304.5 \pm 528.9 $\mathrm{nm}$. The REV method yields a liposome with a particle size of $2,643.5 \pm 350.8 \mathrm{~nm}$. The polydispersity index shows the distribution of liposome size. The TLH method produces liposome with a polydispersity index of $1,490 \pm 0.284$. The REV method produces liposome with a polydispersity index of $1.987 \pm 0.901$.
\end{abstract}

Keywords: Caesalpinia sappan L., Liposome, Thin Layer Hydration method,

Reversed Phase Evaporation method.

\section{INTRODUCTION}

The increased incidence of adverse drug-induced side effects has not only incited the researcher to look for new drugs that are safe to use, but also to find ways to deliver the drug well. A drug delivery system is needed to deliver the drug directly to the target without disturbing the surrounding environment, thus reducing side effects and improving the effect of the drug. Some of the existing drug delivery systems are nio some, resealed erythrocytes, pharmacosomes, and liposome. Among the drug delivery systems, liposome is one of the fastest growths ${ }^{1,2,3}$.

This is an Open Access article licensed under a Creative Commons Attribution-Non Commercial-Share Alike 4.0 International License (https://creativecommons.org/licenses/by-nc-sa/4.0/), which permits unrestricted Non Commercial use, distribution and reproduction in any medium, provided the original work is properly cited. 
The liposome is a round vesicle having a water core portion surrounded by one or more lipid concentrates to form a double layer lipid membrane. Due to its unique structure, liposome can be used to deliver water and fat soluble drug molecules. Hydrophilic molecules are present in compartments containing water and lipophilic molecules in double layer fat ${ }^{4,5,6}$.

Liposome is a good drug delivery system because it has characteristics such as biodegradable, non-toxic, flexible that can deliver both hydrophilic and lipophilic drugs, increase efficacy and therapeutic index, and improve drug stability through encapsulation ${ }^{7}$. Liposome has been widely used as a drug delivery system such as anticancer drugs ${ }^{8}$, antibacterials ${ }^{9}$, antifungals ${ }^{10}$, vaccines ${ }^{11}$, and medications for asthma ${ }^{12}$. Liposome is not only can be used as a drug delivery system in synthetic drugs but it can also be used as a system of delivery of compounds from plants that can be utilized in treatment ${ }^{13}$.

Research on medicinal plants and new medicines derived from nature has increased over the past four decades. This can be attributed to the fact that the available synthetic drugs are too expensive and tend to carry unwanted side effects 14 . One plant that has been widely used for treatment is Sappan (Caesalpinia sappan L.).

Sappan (Caesalpinia sappan L.) is a widespread plant of the Caesalpiniaceae family in Southeast Asia. This plant has been used for anti-inflammatory ${ }^{15}$, hepatoprotective ${ }^{16}$, anti influenza ${ }^{17}$, antioxidant, antelmintic ${ }^{14}$, analgesic ${ }^{18}$, and immunomodulator ${ }^{19}$. Caesalpinia sappan $L$ is also potential for cancer treatment ${ }^{20,21}$.

Components of active compounds contained in Caesalpinia sappan L. are brazillin, brazilein, sapanon, kalkon, sapankalkon and other common components, such as amino acids, carbohydrates and palmitic acid which are relatively small amounts ${ }^{22}$. The wood part of Caesalpinia sappan L. contains phenolic compounds such as 4-O-methylsappanol, protosappanin A, protosappanin B, brazilin, brazilein, and sapankalkon ${ }^{23}$. Brazilin is the main active ingredient found in the wood of Caesalpinia sappan L. ${ }^{24}$. Plants that contain many phenolics are known to have high antioxidant activity because it can capture free radicals and inhibit the enzyme responsible for the formation of free radicals ${ }^{25,26}$. But its use is limited due to polyphenol instability27.

Because the nature of the compounds contained in the wood is unstable, a method that can maintain its stability is required. One such method is by using liposome. This study aims to determine the characteristics of liposomes made using two methods including organoleptis, morphology, particle size and particle size distribution.

\section{MATERIALS AND METHODS}

\section{Materials}

Caesalpinia sappan L. wood was collected in Solo, Central Java, Indonesia. Phosphatidylcholine and cholesterol were purchase from Sigma-Aldrich, Singapore. chloroform, n-hexane, ethyl acetate and ethanol bought from Merck \& Co, German. Potassium dihydrogen phosphate, sodium hydroxide and aquadest were bought from Brataco, Indonesia

\section{Preparation of SWEAF}

Caesalpinia sappan L. wood were dried and ground into a fine powder, and then extraced with $70 \%$ ethanol at room temperature for 3 days. The combined filtrate was collected three times by filter paper, and the solvent was evaporated using a rotary evaporator to obtain a thickened Sappan wood extract. A total of $40.05 \mathrm{~g}$ of viscous Sappan wood extract was dissolved in $500 \mathrm{~mL}$ of ethanol and $500 \mathrm{~mL}$ of water. After forming a clear solution of reddish-brown, ethanol was evaporated using a rotary evaporator. After all ethanol has evaporated, the water containing the wood extract Sappan was inserted into the separating funnel then fractionated with $\mathrm{n}$-hexane solvent with a ratio of $1: 1$ solvent $(500 \mathrm{~mL}: 500 \mathrm{~mL}$ ). The separating funnel was then shaken to mix both water solvents and $\mathrm{n}$-hexane, after which it was left so that there were two layers of water and $n$-hexane. The fractionation with the $n$-hexane solvent was performed until a clear $\mathrm{n}$-hexane was obtained. Furthermore, the water layer was fractionated with ethyl acetate in a ratio of $1: 1$ $(500 \mathrm{~mL}: 500 \mathrm{~mL})$ to obtain two layers of water and ethyl acetate. The fractionation process with ethyl acetate was carried out until a clear layer of ethyl acetate. The SWEAF was concentrated with a rotary evaporator to obtain a thick ethyl acetate fraction. 
Table 1: Liposome Formula

\begin{tabular}{lccc}
\hline & \multicolumn{3}{c}{ Liposome component } \\
$\begin{array}{l}\text { SWEAF } \\
(\mathrm{mg})\end{array}$ & $\begin{array}{c}\text { Molar } \\
\text { Ratio }\end{array}$ & $\begin{array}{c}\text { Phosphatidylcholine } \\
(\mathrm{mg})\end{array}$ & $\begin{array}{c}\text { Cholesterol } \\
(\mathrm{mg})\end{array}$ \\
\hline 20 & $1: 1$ & 79,82 & 40,18 \\
\hline
\end{tabular}

Preparation of Liposome

The Thin Layer Hydration Method

The phosphatidylcholine, cholesterol and SWEAF were weighted by the amount according to the formula shown in Table 1. Cholesterol (mg) and phosphatidylcholine $(\mathrm{mg})$ were dissolved in $10 \mathrm{~mL}$ of chloroform. The solvent was then evaporated using a rotary evaporator at $50{ }^{\circ} \mathrm{C}$. The solvent was evaporated to form a thin layer on the bottom wall of the flask, which is a lipid layer of liposomes. The lipid layer formed was hydrated with $10 \mathrm{~mL}$ of a phosphate buffer solution of $\mathrm{pH} 7.4$ containing SWEAF. Rotary evaporator was ignited without vacuum for $1 \mathrm{~h}$ until multilamellar vesicle liposome (MLV) was formed. The liposome obtained was then synchronized with a sonicator bath for $45 \mathrm{~min}$. in order to size into a small unilamellar vesicle (SUV) $)^{13,28,29}$.

\section{The Reverse Phase Revealing Method}

The phosphatidylcholine, cholesterol and SWEAF were weighted by the amount according to the formula shown in Table 1. Phosphatidylcholine ( $\mathrm{mg}$ ) and cholesterol (mg) were dissolved in $30 \mathrm{ml}$ of chloroform. The SWEAF was dissolved in $10 \mathrm{~mL}$ phosphate buffer solution $\mathrm{pH}$ 7.4. Then the two phases were mixed and sonicated with bath sonicator for 10 minutes. The result of sonication was inserted into the flask, then the solvent was evaporated with a rotary evaporator at $50{ }^{\circ} \mathrm{C}$ to

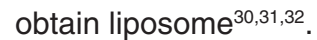

\section{Evaluation of Liposomes}

\section{Organoleptic Examination}

The liposome suspension was observed visually. The results obtained were recorded $^{33}$.

2. Evaluation of morphology by using Transmission Electron Microscopy (TEM) The sample was dripped on a carbon coated cooper grid of one drop and allowed to stand for one minute to dry, then added one drop of $2 \%$ acetate uranil and let stand one minute at room temperature, then analyzed with $\mathrm{TEM}^{34}$.
3. Particle Size Determination and Distribution

Evaluation was done by using Particle Size Analyzer (PSA) with light scattering method at $25{ }^{\circ} \mathrm{C}$. Prior to measurement, the sample was dispersed onto the dispersing medium. The dispersing medium used is aquadest, inserted into a fluid tank. The sample was then slowly dripped at the baseline to determine the particle size of the liposomal globules ${ }^{35,36}$.

4. Qualitative test of the SWEAF and liposome with TLC

Liposomes were centrifuged for $30 \mathrm{~min}$. at $11,000 \mathrm{rpm}$ to separate supernatants and precipitates 13,36. The SWEAF absorbed (precipitate) and the SWEAF free (supernatant) was dropped on TLC plate to determine Rf value with butanol : acetic acid : water $(2: 0,5: 2)$ as mobile phase.

\section{RESULTS}

After conducting research on the making of liposome with active compound of the SWEAF, it is revealed that.

1. SWEAF as much as $2.51 \mathrm{~g}$ was obtained from $40.05 \mathrm{~g}$ of viscous Sappan wood extract with a yield of $6.27 \%$ by weight of viscous extract.

2. The examination of organoleptic SWEAF shows that the fraction is thick, reddish brown, odorless, and bitter.

3. The results of the making of liposomes with TLH and REV methods obtained red liposomes with an egg-like smell. The results are as shown in Figure 1.

4. Examination using Transmission Electron Microscopy (TEM), liposomes prepared by TLH and REV methods have morphology of round and unilamellar vesicles namely water cores surrounded by a layer of lipid which can be seen in Figures 2 and 3.

5. The results of the measurement of liposomal particles from the TLH and the REV methods show that the average size of liposome particles prepared by TLH method is smaller than the average size of liposomal particles prepared by REV method (Table 2). The results of statistical analysis with t test note that the liposomal particle size of the two methods do not differ significantly. 
6. The result of determination of particle size distribution shows that the liposome polymerization index value of TLH method is smaller than liposome from REV method (Table 3). The result of statistical test with $t$ test shows that the particle size distribution of both methods does not differ significantly.

7. The results of qualitative test of the SWEAF, the SWEAF absorbed (precipitate) in liposome and the SWEAF free (supernatant) by using thin layer chromatography with butanol : acetic acid : water (2: 0, 5: 2) show three parallel spots that indicate that the compound contained in all three is the same. This can be seen in Figures 4 and 5 .

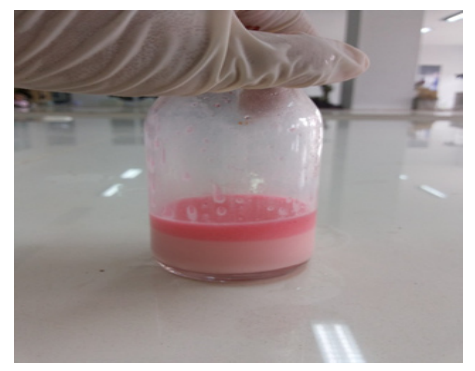

Fig. 1. A mixture of phosphatidylcholine and cholesterol in chloroform and SWEAF in a phosphate buffer solution pH 7.4 after sonication

A

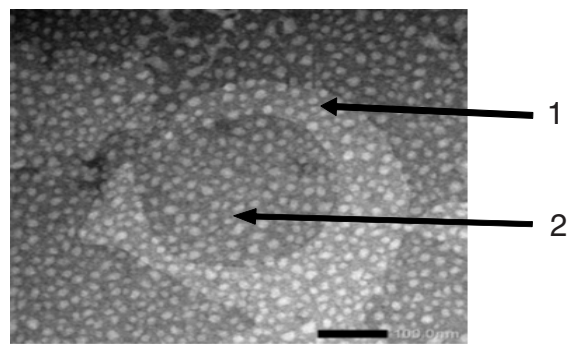

B

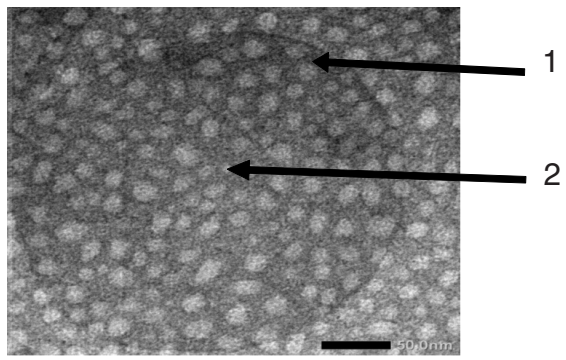

Fig. 2. Morphology and liposomal lamellarity under TEM with TLH method (A) Magnification $40000 \times$; (B) $80000 \times$ magnification; 1 . The lipid section; 2 . The water core part

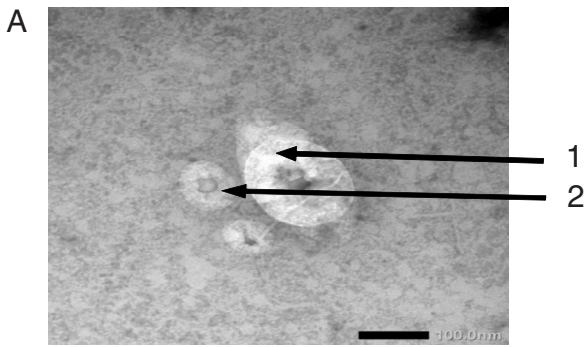

B

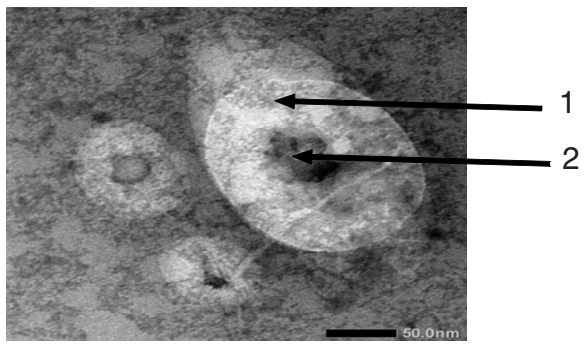

Fig. 3. Morphology and liposomal lamellarity under TEM with REV method (A) Magnification $40000 \times$; (B) $80000 \times$ magnification; 1 . The lipid section; 2 . The water core part

\section{DISCUSSION}

In this research, liposome was prepared with active compound of SWEAF. Sappan is known to have high antioxidant activity ${ }^{25,26}$. The composition of liposome prepared can be seen in Table 1. The SWEAF was obtained from the fractionation of the viscous extract of Sappan wood. Viscous Sappan wood extract obtained from previous researchers.

In this study, the preparation of liposomes with active compound of SWEAF using two methods namely TLH method and REV method. The reason for choosing these two methods is that they more practical and simple, considering the availability of tools in the laboratory, and the resulting liposomes can absorb medication up to $65 \% 4,29$.

Liposomal suspension resulting from the TLH method is as red as the color of the SWEAF with the egg-like smell because it uses phosphatidylcholine derived from the egg. The color of the liposomal suspension obtained depends on the color of the active compound used.

The result of the observation of the morphology of liposomes prepared by TLH and REV methods shows that liposomes are round and unilamellar and contain core water surrounded by 
a lipid layer which can be seen in Fig. 2 and 3. The results of previous studies conducted by Verawaty ${ }^{36}$, $\mathrm{Naeem}^{34}$, and Anabousi ${ }^{37}$ on the preparation of liposomes by using TLH method obtained similar results. Previous studies on the production of liposomes with REV methods conducted by Mishra $^{38}$, Pentak ${ }^{39}$, and Moscho ${ }^{40}$ also made similar discovery.

Table 2: Particle size of Liposome

\begin{tabular}{lcccc}
\hline Method & \multicolumn{3}{c}{ Diameter (nm) } & Mean \pm SD \\
& Preparation I & Preparation II & Preparation III & \\
\hline $\begin{array}{l}\text { Thin layer } \\
\text { hydration }\end{array}$ & 1884.5 & 2898.5 & 2130.4 & $2304.5 \pm 528.9$ \\
$\begin{array}{l}\text { Reverse phase } \\
\text { evaporation }\end{array}$ & 2843.2 & 2848.9 & 2238.4 & $2643.5 \pm 350.8$ \\
\hline
\end{tabular}

Table 3: Polidispersity index of Liposom

\begin{tabular}{lcccc}
\hline Method & \multicolumn{3}{c}{ Polidispersity index } & Mean \pm SD \\
& Preparation I & Preparation II & Preparation III & \\
\hline $\begin{array}{l}\text { Thin layer } \\
\text { hydration }\end{array}$ & 1.418 & 1.248 & 1.803 & $1.490 \pm 0.284$ \\
$\begin{array}{l}\text { Reverse phase } \\
\text { evaporation }\end{array}$ & 2.905 & 1.104 & 1.953 & $1.987 \pm 0.901$ \\
\hline
\end{tabular}

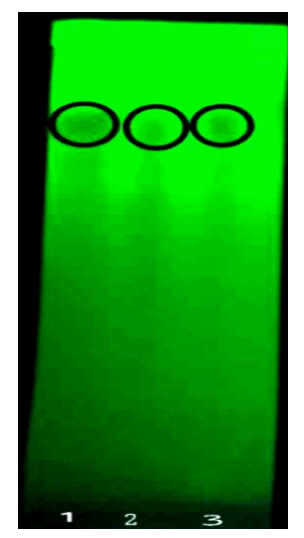

Fig. 4. TLC platform of liposome testing of TLH method; 1. SWEAF (Rf 077); 2. Precipitate (Rf 0.77); 3. Supernatant (Rf 0.77).

Liposome particle size was obtained by the TLH method from the first to third preparation at $1884.5 \mathrm{~nm}, 2898,5 \mathrm{~nm} ; 2130.4 \mathrm{~nm}$ with an average of $2304.5 \pm 528.9$ (see Table 2). The preparation of liposomes with a TLH method will produce a liposome with Multilamellar Vesicles (MLV) type, which will become Small Unilamellar Vesicles (SUV) after the liposomal sonication process. But from

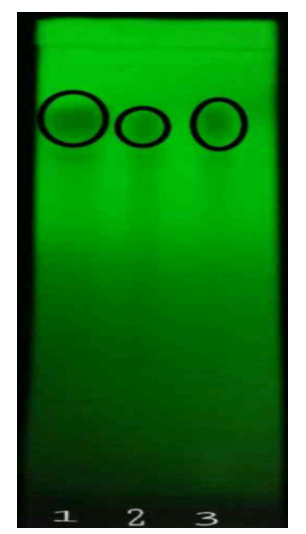

Fig. 5. TLC platform of liposome testing of REV method; 1. SWEAF (Rf 0.77); 2. Precipitate (Rf 0.76); 3. Supernatant (Rf 0.77)

the measurements, the liposomes obtained have a type of Giant Unilamellar Vesicles (GUV) where the liposome has a size $>1000 \mathrm{~nm}$.

The results of the evaluation of liposomal particle size from the TLH method performed by Aukunuru $^{13}$ obtained liposomes with particle sizes above 5000 nm including Giant Unilamellar Vesicles 
(GUV). A study conducted by Chen $^{35}$ obtained a particle size of $785.1 \mathrm{~nm}$ liposomes that included Large Unilamellar Vesicles (LUV). A study conducted by Verawaty ${ }^{36}$ obtained a liposome particle size of the same formula of $2977.5 \mathrm{~nm}$ which included Giant Unilamellar Vesicles (GUV). The size of the liposomal particles obtained by the REV method from the first to third manufacture respectively is $2843.2 \mathrm{~nm}$; $2848.9 \mathrm{~nm} ; 2238.4 \mathrm{~nm}$ with an average of 2643.5 \pm 350.8 (Table 3 ). The results of the evaluation of liposomal particle size from the REV method by Elorza ${ }^{31}$ obtained $238 \mathrm{~nm}$ liposomes including Large Unilamellar Vesicles (LUV). Research conducted by Yang $^{32}$ obtained liposomes type Large Unilamellar Vesicles (LUV) with a size of $206.4 \mathrm{~nm}$. Further research conducted by Chen35 obtained liposomes with a particle size of 551.1 which includes Large Unilamellar Vesicles (LUV). The results of previous studies found the appropriate liposome size as expected, whereas the production of liposomes with reversed phase evaporation method yielded liposomes with the type of Large Unilamellar Vesicles (LUV) with the size of $100-1000 \mathrm{~nm}$, but the results of liposomes measurements obtained from the REV method in this study has a size> $1000 \mathrm{~nm}$ belonging to the Giant Unilamellar Vesicles (GUV). The liposomes obtained from the TLH method have an average particle size smaller than the liposomes obtained from REV methods. The result of statistical analysis using t test obtained significance value of 0.407 where the significance value of 0.05 indicates that the liposomes particle size of the two methods did not differ significantly.

Analysis using Particle Size Analyzer (PSA) also obtained polydispersity index. The polydispersity index is a parameter for determining the particle size distribution of nanoparticles. The range of polydispersity index values is from 0.01-0.7 for monodispersion and $>0.7$ for polydispersion 41 . The liposomal polymerisation results from the TLH method and the REV method give an average polydispersity value of $1,490 \pm 0.284$ and 1.987 \pm 0.901 . The liposomal polydispersity index of the TLH method is smaller than liposomes prepared by REV methods. The result of statistical analysis using t test from both methods did not differ significantly. The polydispersity index shows that the liposomes obtained from both methods are polydispersed with a high polydispersity value. A high polydispersity index indicates that the particles formed are not dispersed uniformly so that it tends to aggregate causing enlargement of the liposome particle size. Qualitative testing of the SWEAF and liposome with active ingredient of SWEAF by using thin layer chromatography to ensure that the SWEAF is present in the liposome prepared. TLC plate shows a partial stain, which indicates that the SWEAF absorbed in liposome.

\section{CONCLUSION} concluded that

Based on the results of this study, it can be

1. Liposomes prepared with a TLH method and REV methods have a red color and egg-like smell.

2. Examined with TEM, liposomes prepared with TLH and REV methods have morphologies of round and unilamellar vesicles.

3. Liposomes prepared with TLH method have smaller particle sizes than liposomes prepared with REV method.

4. Liposomes prepared with TLH method have a smaller particle size distribution than those prepared with REV method.

\section{ACKNOWLEDGEMENT}

The research was funded by the Directorate of Research and Community Service of the Directorate General of Research and Development of the Ministry of Research, Technology and Higher Education with Research Contract No. 059/SP2H/ LT/DRPM/IV/2017.

\section{REFERENCES}

1. Shashi, K.; Satinder, K.; Bharat, P. A.; Complete review on: liposomes. IJRP., 2012, 3(7), 10-16.

2. Sipai, A. B. M.; Yadav, V.; Mamatha, Y.; Prasanth, V. V. Liposomes: an overview. JPSI,
2012, 1(1), 13-21.

3. Sirisha, V. N. L.; Harika, I. B.; Sruthi, B.; Namrata, M.; Kirankumar, P.; Kiran, Y.; Rao, O. U. M. Liposomes - the potential drug carriers. IOSR-PHR., 2012, 2(5), 26-38. 
4. Argan, N.; Harikumar, S. L.; Nirmala. Topical liposomal gel : a novel drug delivery system. Int. J. Res. Pharm. Chem., 2012, 2(2), 383391.

5. Laouini, A.; Maalej, C. J.; Blouza, I. L.; Sfar, S.; Charcosset, C.; Fessi, H. Preparation, characterization and applications of liposomes: state of the art. J. Colloid Sci. Biotechnol., 2012, 1(2), 147-168.

6. Kalepu, S.; Sunilkumar, K. T.; Betha, S.; Mohanvarma, M. Liposomal drug delivery system - a Comprehensive Review. Int. J. Drug Dev. \& Res., 2013, 5(4), 62-75.

7. Popovska, O.; Simonovska, J.; Kavrakovski, Z.; Rafajlovska, V. Methods for preparation and characterization of liposomes as drug delivery systems. Int. J. Pharm. Phytopharm. Res., 2013, 3(2), 13-20.

8. Sriraman, S. K.; Salzano, G.; Sarisozen, C.; Torchilin, V. Anti-cancer activity of doxorubicinloaded liposomes co-modified with transferrin and folic acid. Eur. J. Pharm. Biopharm., 2016, 105, 40-49.

9. Shafaa, M. W.; Dayem, S. A.; Elshemey, W. M.; \& Osman, H. M. In vitro antibacterial activity of liposomal cephalexin againts Staphylococcus aureus. Romanian J. Biophys., 2008, 18(4), 293-300.

10. Abdel-Rhaman, M. S.; Soliman, W.; Habib, F.; Fathalla, D. A new long-acting liposomal topical antifungal formula: human clinical study. Cornea., 2012, 31(2), 126-129.

11. Schwendener, R. A.. Liposomes as vaccine delivery systems: a review of the recent advances. Ther. Adv. Vaccines., 2014, 2(6), 159-182.

12. Parmar, J. J.; Singh, D. J.; Hegde, D. D.; Lohade, A.A.; Soni, P. S.; Samad, A.; Menon, M. D.. Development and evaluation of inhalational liposomal system of budesonide for better management of asthma. Indian $\mathrm{J}$. Pharm. Sci., 2010, 72(4), 442-448.

13. Aukunuru, J.; Joginapally, S.; Gaddam, N.; Burra, M.; Bonepally, C. R.; Prabhakar, K.. Preparation, characterization, and evaluation of hepatoprotective activity of an intravenous liposomal formulation of bis-demethoxy curcumin analogue (BDMCA). Int J.Drug Dev.\& Res., 2009, 1(1), 37-46.

14. Harjit, K.; Amini, M. H.; Suttee, A.. Evaluation of antioxidant and anthelmintic properties of Caesalpinia sappan L . leaves. IJPPR., 2016, 8(2), 362-368.

15. Tewtrakul, S.; Tungcharoen, P.; Sudsai, T.; Karalai, C.; Ponglimanont, C.; Yodsaoue, O. Antiinflammatory and wound healing effects of Caesalpinia sappan L. Phytother. Res., 2015, 29(6), 850-856.

16. Srilakshmi, V. S.; Vijayan, P.; Raj, P. V.; Dhanaraj, S. A.; Chandrashekhar, H. R. Hepatoprotective properties of Caesalpinia sappan Linn. heartwood on carbon tetrachloride induced toxicity. Indian J. Exp. Biol., 2010, 48(9), 905-910.

17. Liu, A. L.; Shu, S. H.; Qin, H. L.; Lee, S. M. Y.; Wang, Y. T.; Du, G. H. In vitro antiinfluenza viral activities of constituents from Caesalpinia sappan. Planta Med., 2009, 75(4), 337-339.

18. Hemalatha, K.; Kiran, A. S.; Bannappa, U.; Satyanarayana, D. Analgesic activity of Caesalpinia sappan heartwood. Pharm. Biol., 2007, 45(5), 360-362.

19. Sunitha, V. S.; Sunil, M. A.; Radhakrishnan, E. K.; Mathew, J. Immunomodulatory activity of Caesalpinia sappan $L$. extracts on peritoneal macrophage of albino mice. IJSR., 2015, 4(12), 449-452.

20. Khamsita, R.; Hermawan, A.; Putri, D. D. P.; Meiyanto, E. Ethanolic extract of secang (Caesalpinia sappan L.) wood performs as chemosensitizing agent through apoptotic induction on breast cancer MCF-7 cells. IJCC., 2012, 3(3), 445-450.

21. Son, H. L.; Linh, N. L. Q.; Minh, T. Van. Isolation and in vitro anticancer activity of flavonoids from to moc (Caesalpiniaa sappan Linn.). Journal Science., 2015, 3(3), 24-30.

22. Nirmal, N. P.; Prasad, R. G. S. V; Keokitichai, S. Wound healing activity of standardized brazilin rich extract from Caesalpinia sappan heartwood. J. Chem. Pharm. Res., 2014, 6(10), 195-201.

23. Batubara, I.; Mitsunaga, T.; Ohashi, H. Brazilin from Caesalpinia sappan wood as an antiacne agent. J. Wood. Sci., 2010, 56(1), 77-81.

24. Nirmal, N. P.; Rajput, M. S.; Prasad, R. G. S. V.; Ahmad, M. Brazilin from Caesalpinia sappan heartwood and its pharmacological 
activities : a review. Asian Pac. J. Trop., 2015 8(6), 421-430.

25. Badami, S.; Moorkoth, S.; Rai, S. R.; Kannan, E.; Bhojraj, S. Antioxidant activity of Caesalpinia sappan heartwood. Biol. Pharm. Bull., 2003, 26(11), 1534-1537.

26. Hu, J.;Yan, X.;Wang, W.;Wu, H.; Hua, L.; Du, L. Antioxidant activity in vitro of three constituents from Caesalpinia sappan L. Tsinghua Sci. Technol., 2008, 13(4), 474-479.

27. Permana, A. D.; Utami, R. N.; Ramadhani, A.; Dewy, M.; Sugara, B. Formulation and evaluation microcapsules Of Caesalpinia Sappan Linn . using emulsion solvent evaporation method. Int. J. Technol. Enhanc. Merg. Eng. Res., 2015, 3(7), 121-125.

28. Hathout, R. M.; Mansour, S.; Mortada, N. D.; Guinedi, A. S. Liposomes as an ocular delivery system for acetazolamide: in vitro and in vivo studies. AAPS Pharm. Sci. Tech., 2007, 5(8), E1-E12.

29. Dua, J. S.; Rana, A. C.; Bhandari, A. K. Liposome: methods of preparation and applications. Int. J. Pharm. Stud. Res., 2012, 3(2), 14-20.

30. Giulio, A. D.; Maurizi, G.; Odoardi, P.; Saletti, M. A.; Amicosante, G.; Oratore, A. Encapsulation of ampicillin in reverse-phase evaporation liposomes : a direct evaluation by derivative spectrophotometry. Int. J. Pharm., 1991, 74(2-3), 183-188.

31. Elorza, B.; Elorza, M. A.; Frutos, G.; Chantres, J.R. Characterization of 5-fluorouracil loaded liposomes prepared by reverse-phase evaporation or freezing-thawing extrusion methods: study of drug release. BBA Biomembranes., 1993, 1153(2), 135-142.

32. Yang, S.; Chen, J.; Zhao, D.; Han, D.; Chen, $X$. Comparative study on preparative methods of DC-Chol/DOPE liposomes and formulation optimization by determining encapsulation efficiency. Int. J. Pharm., 2012, 434(1-2),
155-160.

33. Anwekar, H.; Patel, S.; Singhai, A. K. Liposome- as drug carriers. Int. J. of Pharm. \& Life Sci., 2011, 2(7), 945-951.

34. Naeem, S.; Kiew, L. V.; Chung, L. Y.; Ashraf, M. A.; Misran, M. Bin. Liposomes as amphiphilic carriers: encapsulation and stability aspects. Sains Malaysiana., 2016, 45(1), 71-77.

35. Chen, G., Li, D.; Jin, Y.; Zhang, W.; Teng, L.; Bunt, C.; Wen, J. Deformable liposomes by reverse-phase evaporation method for an enhanced skin delivery of (+)-catechin. Drug. Dev. Ind. Pharm., 2014, 40(2), 260-265.

36. Verawaty; Halim, A.; Febriyenti. Efektivitas sistem penghantaran liposom pada katekin sebagai antioksidan. Jurnal Sains Farmasi \& Klinis., 2016, 2(2), 176-182.

37. Anabousi, S.; Laue, M.; Lehr, C. M.; Bakowsky, U.; Ehrhardt, C. Assesing transferrin modification of liposomes by atomic force microscopy and transmission electron microscopy. Eur. J. Pharm. Biopharm., 2005, 60(2), 295-303.

38. Mishra, N.; Gupta, P. N.; Mahor, S.; Khatri, K.; Goyal, A. K.; Vyas, S. P. Liposomes as adjuvant for combination vaccines. Indian $\mathrm{J}$. Exp. Biol., 2007, 45(3), 237-241.

39. Pentak, D.; Sulkowski, W. W.; Maslanka, S.; Wolinska, A.; Duber, S.; Sulkowska, A. Characteristic of liposomes prepared by the modified reverse-phase evaporation method 31P-NMR and TEM study. Macromal. Symp., 2006, 245(1), 476-484.

40. Moscho, A.; Orwar, O.; Chiu, D. T.; Modi, B. P.; Zare, R. N. Rapid preparation of giant unilamellar vesicles. Proc. Natl. Acad. Sci., 1996, 93(21), 11443-11447.

41. Nidhin, M.; Indumathy, R.; Sreeram, K. J.; Nair, B. U. Synthesis of iron oxide nanoparticles of narrow size distribution on polysaccharide templates. Bull. Mater. Sci., 2008, 31(1), 93-96. 